\title{
Influence of wind power production on electricity market price
}

\author{
Gunars VALDMANIS ${ }^{1 *}$, Gatis BAZBAUERS ${ }^{2}$ \\ ${ }^{1,2}$ Riga Technical University, Institute of Energy Systems and Environment, Āzenes iela 12-K1, \\ Riga, LV-1048, Latvia
}

\begin{abstract}
The study looks for a correlation between the share of wind power and electricity wholesale prices in the selected regions of the Nordic Baltic power market "Nord Pool Spot". The aim is to see if and how strong an impact of wind power production has on power market prices. This information would help to perform long-term energy system analysis considering growing wind energy penetration. The actual hourly wind production and power consumption data as well as electricity prices from the year 2019 were used in the analysis. Results of the study revealed that in the analysed dataset there is no correlation between the share of wind power and the power prices, i.e. $R$-squared value is 0.003 for the Baltic region and 0.0064 for both trading areas of Denmark. In contrast, the R-squared value was almost 0.6 for a positive correlation between power demand and prices. The results mean that expected loss of interest to invest due to falling power prices, as a share of renewable power increases, should be examined more carefully and may not fulfil forecasts of policy makers and industry experts.
\end{abstract}

Keywords - Electricity market; electricity prices; renewable energy sources; wind power.

\section{INTRODUCTION}

Renewable energy sources, especially wind and solar energy, are becoming an increasingly important energy supply source both in European countries and other world regions. In line with the statistics from such sources as Nordic power exchange "Nord Pool Spot", already now the share of wind power can be seen as high, i.e. $30 \%$ (see Fig. 1). Thus, at certain periods wind energy becomes the second largest source of power in the Nordic and Baltic region for prolonged periods of time, and at certain moments even the largest source of power for the region. Meanwhile, in certain countries, e.g. Denmark, the production volume of wind power can easily surpass the overall power consumption of the country. Due to the fact that wind and solar power plants require no fuel, and their operation does not produce greenhouse gas emissions, and their technological competitiveness is increasing, a great number of policy makers view wind and solar energy among the most perspective future energy sources. Absence of significant short-run marginal costs, in comparison with fuel and labour costs of many conventional power production technologies, have led to significant discussions within the power industry about the impact of these energy sources on wholesale electricity prices. Overall consensus exists that, all in all, wind and solar energy are likely to apply downward pressure on power prices. However, it is important to keep in mind, that without other market mechanisms or subsidies a decline of prices in the power market, in which the marginal costs

* Corresponding author.

E-mail address: gunars_valdmanis@inbox.lv 
as well as demand and supply are the main price setting factors, it can become challenging to maintain sustainable prices which would support future investments in power production. Namely, a decreased level of power prices during high-wind periods may jeopardize incentives for additional investments in renewable energy production sources [1], [2]. Thus, forecasting of future power price development in relation to increased penetration of wind and solar energy becomes an increasingly important task for both policy makers and investors.

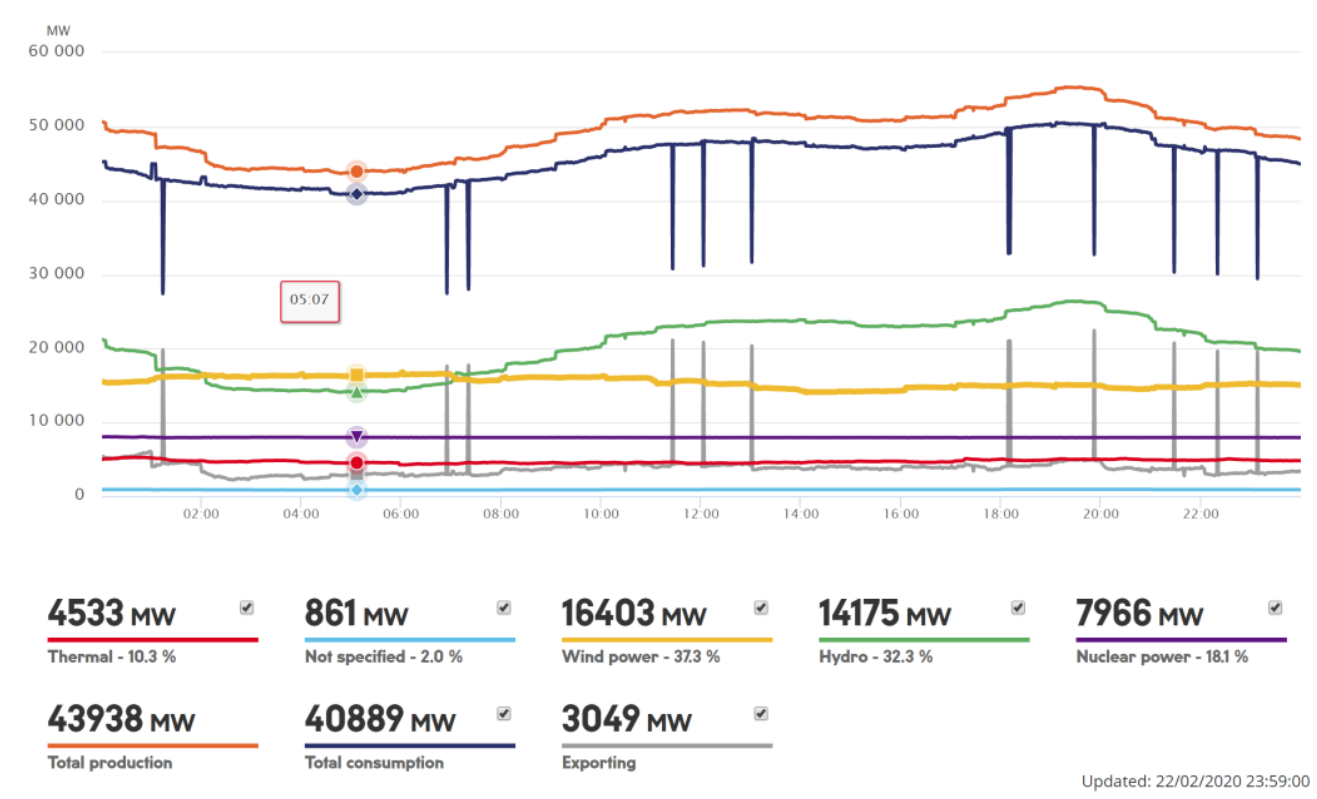

Fig. 1. Balance by production sources of the Nordic and Baltic power system on February 22, 2020. Source: www.stattnet.no; www.ast.lv; Nord Pool Spot.

The topicality and scientific importance of this study is substantiated by the fact that most European Union countries, including Latvia, have adopted increasing renewable energy production and their proportion in the overall energy balance in the next decades as one of their political priorities. Also several industry organisations predict increased usage of wind and solar energy as the inevitable direction towards which the energy industry should develop [3]-[5]. However, the existing research and forecasts do not provide a clear answer about the economic impact of such development trends and policies to support wind and solar energy [6]. While several earlier publications and studies show that generally, with an increased penetration of wind energy in power markets, wholesale electricity prices decline, there are several considerations why the results and conclusions of these studies may require reevaluation. First of all, many of these results clearly point at significant differences in the correlation between wind production and prices in various power markets. Also, many of the results have been obtained from analysis of periods when the proportion of wind energy in particular energy systems was lower than it is nowadays [7]-[9].

It is also important to note that some of the publications and analysis [10], [11] were mostly based on daily or monthly statistics, while the actual data from "Nord Pool Sport" exchange clearly reveals that price and production fluctuation is far more significant on an hourly basis. 
Daily or monthly average prices most likely do not always correctly reflect the actual economic performance of wind energy producers and impact of wind power production on wholesale electricity prices. Statistics, which reflect the price dynamics on an hourly basis and the respective income of wind energy producers, is, in our opinion, more suitable to measure the economic performance of producers and their impact on the market in general.

Intensive research work on the effect of wind energy production on the behaviour of power markets has been carried out by several researchers for more than a decade, and several publications imply that increase of wind energy production and subsequent growth in the proportion of wind energy in the overall energy balance should result in a gradual decline of wholesale power prices [10], [12], [2], [13]. A research carried out in Sweden for the period from the year 2000 to 2016 confirmed that, with the increase of wind energy production by $1 \%$, the wholesale electricity price decreased by approximately $0.08 \%$, and over a longer period this value may increase to approximately $0.1 \%$ [14].

However, the methodology used in this research, cannot be fully applied to the existing power market situation or forecasting, because the proportion of wind energy in the analysed region has already significantly increased and, possibly, analyses no longer accurately characterize the current situation. Moreover, the study is based on monthly data, which, in line with the actual observations of price fluctuations on an hourly or daily basis, do not always fully reflect the full magnitude of wind energy production and price volatility, as well as proportion of wind energy in power balance.

While there are a notable number of publications analysing the impact of increase in wind energy production and installed capacity of wind power plants on the wholesale electricity market, in many cases researchers have focused their analysis on the issues, which possibly limit their applicability in the long-term energy system modelling. For example, a study on integration of wind power in energy systems [11] focuses on identifying the most costeffective solutions of flexibility by analysing and comparing costs (i.e. capital costs, fuel, carbon-dioxide and labour costs) on a yearly basis. The researchers in their publication, however, acknowledge, that in general, increase of the proportion of the wind power in energy systems has a positive impact on costs for end-consumer. At the same time, this development jeopardizes investment sustainability for the wind energy industry.

Meanwhile, studies about the impact of wind energy on power market prices in relation with availability of cross-border capacities in Denmark and Ireland suggest that high wind power production in a combination with good availability of cross-border capacities facilitate reduction of power prices and convergence of prices among different regions [15]-[17]. However, these results also show that, from the point of view of the wind power production industry, a reduction of power prices in the wholesale market cannot always be seen as a desirable market development trend. The study does not provide sufficient data to assess a correlation between wind power production and prices in markets with a very high degree of economic and technical integration with neighbouring areas, as the Baltic countries, Denmark, Norway, Sweden and Germany. At the same time, a number of authors acknowledge that in the case if forecasts about the impact of wind and solar energy on power prices will fulfil, industry experts will have to consider introduction of new market mechanisms to maintain economic sustainability for power producers in the longer term, e.g., with the help of capacity payments [18], [1], [19].

The aim of this paper is to investigate and analyse the actual correlation between wind electricity production and its proportion in the actual power demand with the wholesale prices of power in Baltic countries and selected Nordic countries in the year 2019. The obtained correlation data can be used for preparation of further methodological approaches in 
modelling of energy systems, especially in long-term modelling with periods of 20 years or more. The additional potential aim of this study is to identify whether the existing functioning principles of such markets as "Nord Pool Spot" are sufficiently adaptable to accommodate an increasingly large proportion of non-dispatchable energy sources without jeopardizing incentives for additional investments in renewable energy production sources.

\section{Methods}

The study is based on analysis of the actual data of 2019 , including the hourly prices of the "Nord Pool Spot" energy exchange for specific countries, physical production of wind energy in each specific hour and share of the wind produced electricity in the overall power consumption for the specific hour. The data were processed with "Microsoft Excel", to find out whether there is a significant correlation between wind production and power prices, i.e. higher prices at lower share of wind production and vice versa. Due to the availability of hourly data on specific countries from "Nord Pool Spot" exchange and national grid operators, the analysis was carried out for two regions - Denmark, consisting of two trading areas, as well as for the Baltic region, consisting of Latvian, Lithuanian and Estonian trading areas. The hourly price for each region was calculated as the average price of the area-specific prices, while the production of wind power for each region was calculated as a sum of wind energy production in the respective areas. A proportion of wind power in the electricity balance was calculated as percentage of wind power production in respective areas from the aggregated power demand in those areas. Additionally, to compare the possible correlation differences between prices of the hourly and daily market and respective production, an analysis for a wider region, including Denmark, Finland and the Baltic countries, was carried out. In this case, the wind energy production volume consisted of the sum of wind energy production in all countries, while the daily price was the daily average system price of the Nord Pool Spot exchange, which also includes the trading areas of Norway and Sweden. The statistics of wind production of Sweden and Norway were omitted from the analysis due to the fact that the daily or hourly data from these countries were not available. However, data from both the "Nord Pool Spot" exchange and the Norwegian grid operator "Statnett" show that the Nordic and Baltic region is highly homogenous from the point of view of wind power production. In the daily perspective, high wind power production volume in one of the countries indicates high or moderately high wind power production volumes across all "Nord Pool Spot" areas. It must be noted, that due to the "Nord Pool Spot" market functioning principles, one can safely assume that all wind power production that is technically available and deliverable to the grid, is always fully sold in the wholesale market. It is related to the fact that power producers in the wholesale market in the Nordic countries typically compete with marginal production costs, such as fuel costs and variable labour costs. Therefore, nondispatchable production sources with nearly zero or very low marginal costs may participate in the market with atypically low or even negative prices (especially if the power producer additionally to the income from the sales of energy also receives subsidies). Thus, in line with the actual statistics of the "Nord Pool Spot" market, availability of wind production typically signals a high supply of power.

Additionally, an analysis of two shorter time periods for the areas of the Baltic countries, Denmark and Finland was carried out to compare wholesale prices in the situation, when the only significant variable parameter is wind power production, while other important factors, such as power demand, availability of hydro resources, which is characterized by storages in Finland, Norway and Sweden, as well as the ambient air temperature, were similar. 


\section{ReSUlts AND DiscuSSION}

Initial comparison of statistical data obtained from the Nord Pool Spot exchange suggests, that for a short-term period of one week, there is a noticeable correlation between the wind energy production and prices. For the analysis, two 7-day periods in the year 2019 from November 1 to November 7, and from December 3 to December 9 were selected for comparison due to the following considerations: total consumption of power, number of working days, ambient air temperature as well as number of limitations related to availability of production facilities were mostly similar for both periods, and availability of hydro reserve (characterized by the fact that in both periods it exceeded the long-term median value for respective week of the year) during respective analysis period was high. Meanwhile, according to calculations, the difference of wind power production between scenarios exceeded $100 \%$. Thus, the only significant variable parameter for both analys es periods was wind power production. The calculation affirmed that the price difference between scenarios was around $13 \%$, which could be viewed as significant. However, it does suggest, that in longer analysis periods, wind power has a far less impact on fluctuations of the power prices than in shorter periods, which occasionally experienced price differences up to $100 \%$ during 24-hour periods in one specific day, and consistent differences up to $25 \%$ during 24-hour periods.

TABLE 1. COMPARISON OF HIGH AND MODERATE Wind SCENARIOS IN NORDIC COUNTRIES (DATA SOURCE: NORD POOL SPOT)

\begin{tabular}{|c|c|c|c|c|c|c|}
\hline & $\begin{array}{l}\text { Hydro } \\
\text { storage } \\
\text { volume } \\
\text { in Nordic } \\
\text { countries, } \\
\text { MWh }\end{array}$ & $\begin{array}{l}\text { Wind } \\
\text { production in } \\
\text { Baltic countries, } \\
\text { Finland and } \\
\text { Denmark, MWh }\end{array}$ & $\begin{array}{l}\text { Average } \\
\text { market } \\
\text { price, } \\
\text { EUR/MWh }\end{array}$ & $\begin{array}{l}\text { Consumption, } \\
\text { MWh }\end{array}$ & $\begin{array}{l}\text { Share of wind } \\
\text { production in } \\
\text { Nordic-Baltic } \\
\text { consumption, \% }\end{array}$ & $\begin{array}{l}\text { Change in } \\
\text { share of wind } \\
\text { production in } \\
\text { consumption, } \\
\%\end{array}$ \\
\hline $\begin{array}{l}\text { Moderate } \\
\text { wind } \\
\text { scenario }\end{array}$ & 98335 & 335411 & 42.28 & 9013040 & 0.037 & - \\
\hline $\begin{array}{l}\text { High wind } \\
\text { scenario }\end{array}$ & 85178 & 792066 & 37.45 & 9093105 & 0.087 & $134 \%$ \\
\hline
\end{tabular}

Analysis of the yearly data confirms, that despite strong short-term fluctuations related with the changes in the wind power production, there is no correlation between power prices and wind power production in the longer period (Fig. 2). Nord Pool Sport markets responded to the very high volumes of wind power produced (in $\mathrm{MWh}$ ) with relatively moderate price fluctuations, and no significant effect also can be observed for periods with very low wind energy penetration. Meanwhile, the majority of cases when the wholesale power price significantly exceeded or were below the average level, were recorded during periods when wind power production was average, from $40000 \mathrm{MWh}$ to $100000 \mathrm{MWh}$ per day for the region of Finland, Denmark and the Baltic countries. Similar results were observed for hourly analysis in the Baltic region and in Denmark (see Fig. 2 and Fig. 3). 


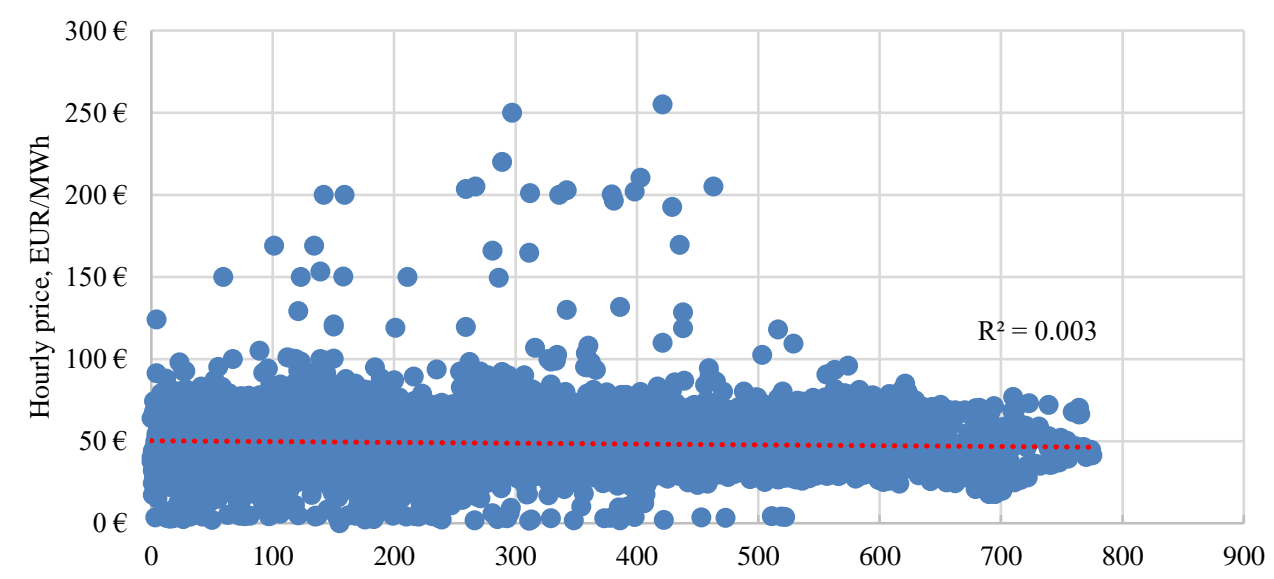

Hourly production of wind energy, MWh

Fig. 2. Correlation between wind power production and power market price on hourly basis in Baltic region during 2019 (Data source: Nord Pool Spot).

While data suggests that the correlation between wind power production and price is higher in Denmark than in Baltic countries (Fig. 2, Fig. 3), for both regions the correlation is very low -0.003 and 0.0064 respectively. It must be also noted that analysis displayed very significant and widely scattered deviations from the overall trend - the highest market prices were recorded both in periods with high wind power supply and with low wind power supply, while the lower market prices in their turn - also both in periods with high wind power supply and low wind power supply.

Identical observations can be made for correlation between the hourly power prices and the share of wind power in the total final power consumption both in Denmark and in the Baltic countries (Fig. 4, Fig. 5). In both cases the correlation was higher than in the case when only wind power production in MWh was considered (and not the share), but it is still very low, i.e. 0.0232 for Baltic countries and 0.0238 for Denmark. It must be also noted that, similarly to the correlation between nominal wind power supply and prices, analysis of wind power proportion in overall demand, also displayed very significant and widely scattered deviations from the overall trend. Namely, the highest market prices were recorded both in periods with high proportion of wind power in the system demand, and with low proportion of wind power in the demand, while the lower market prices in their turn - also both in periods with high wind power proportion in the demand and low wind power proportion in the system demand. 


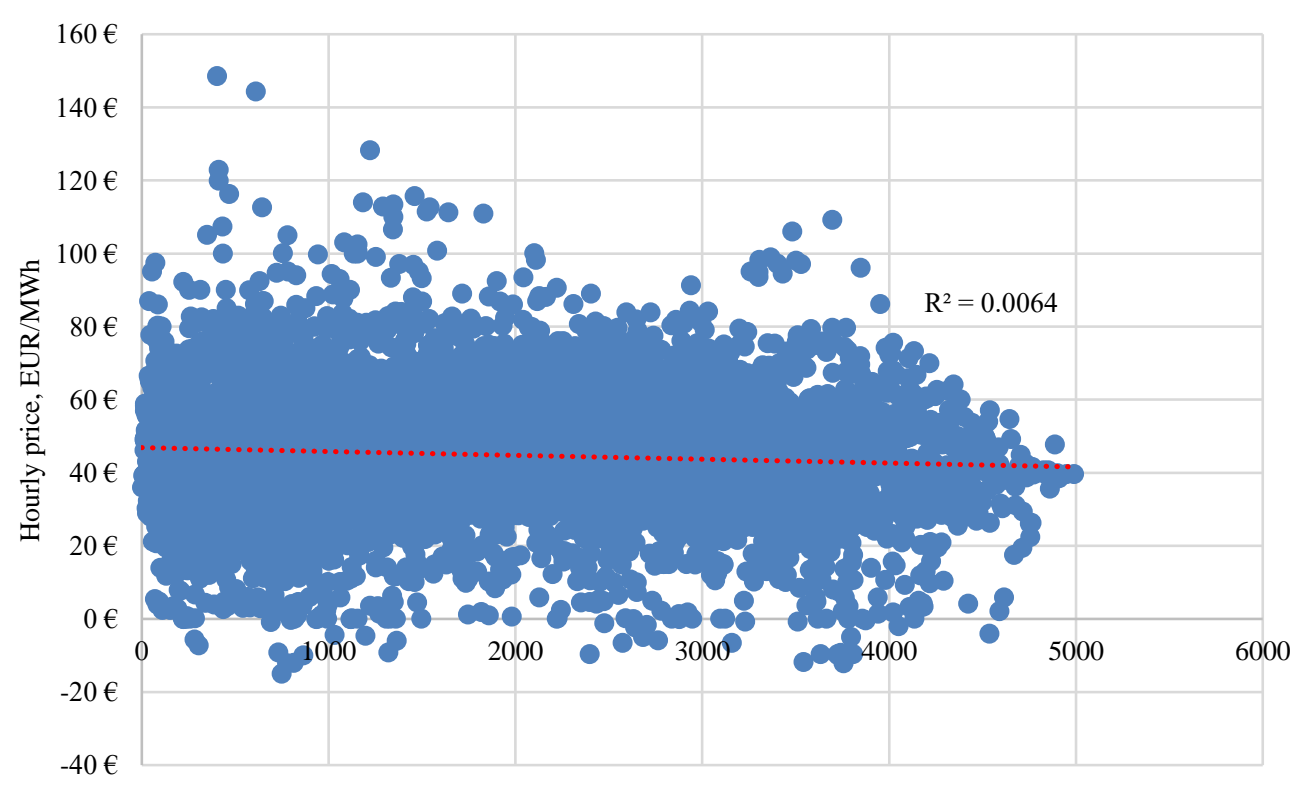

Hourly production of wind energy, MWh

Fig. 3. Correlation between wind power production and power market price on hourly basis in Denmark during 2019 (Data source: Nord Pool Spot).

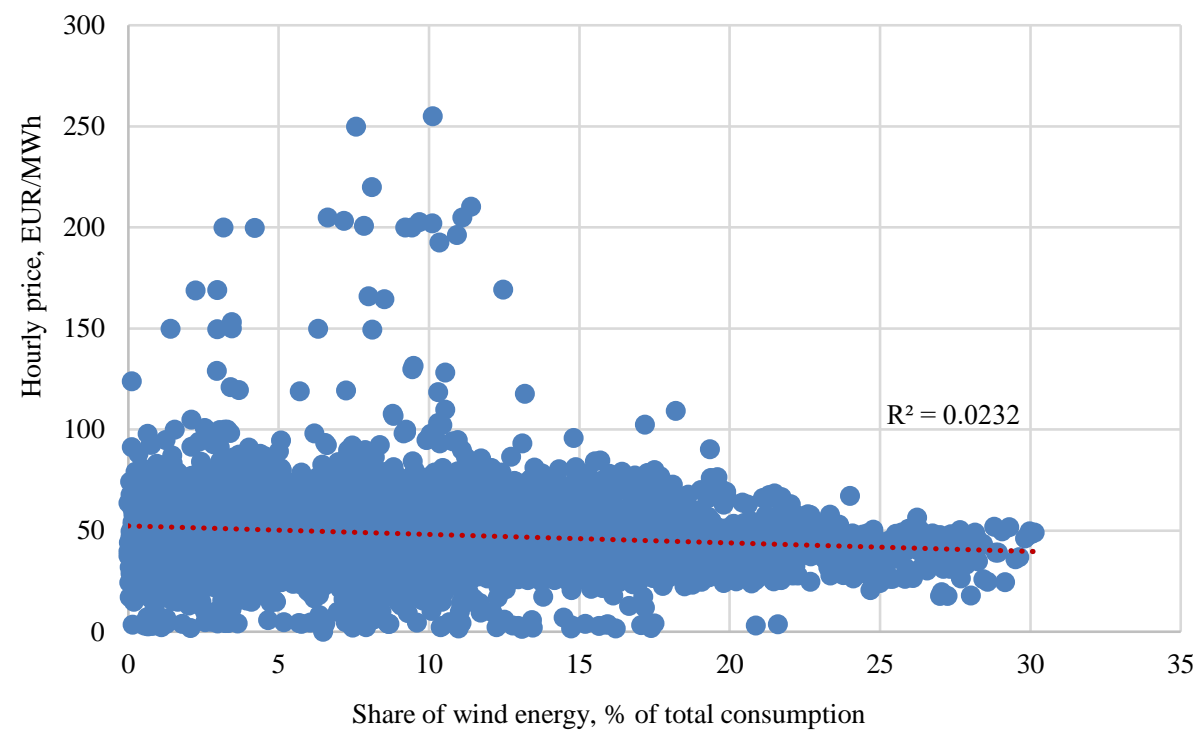

Fig. 4. Correlation between average power market price and share of wind power in the total consumption (demand) in Baltic countries during 2019 (Data source: Nord Pool Spot). 


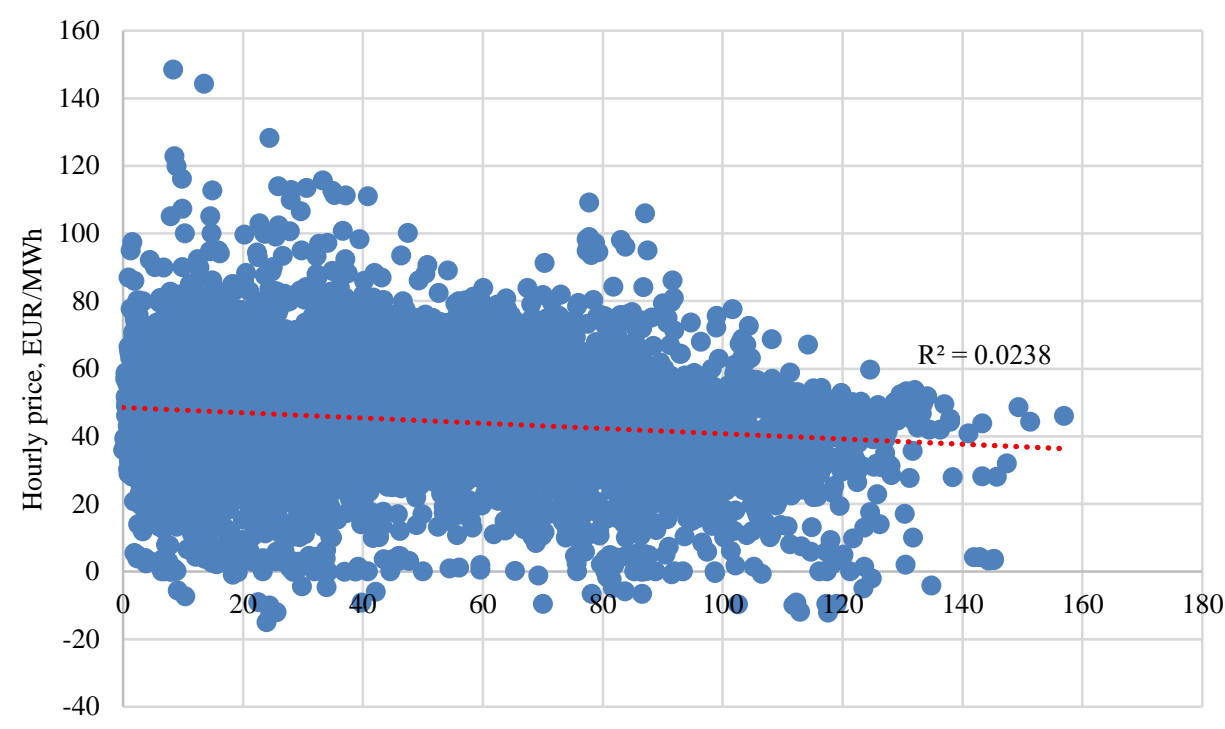

Share of wind energy, $\%$ of total consumption

Fig. 5. Correlation between wind power share in total consumption (demand) and power market price on hourly basis in Denmark during 2019 (Data source: Nord Pool Spot).

Furthermore, analysis performed on the daily power consumption data, showed that the power wholesale prices has a far stronger positive correlation with electricity consumption (Fig. 6), and there were very few deviations from the overall trend - the highest market prices were reached only in periods with a relatively high power demand, while the lower market prices - only in periods with the low power demand.

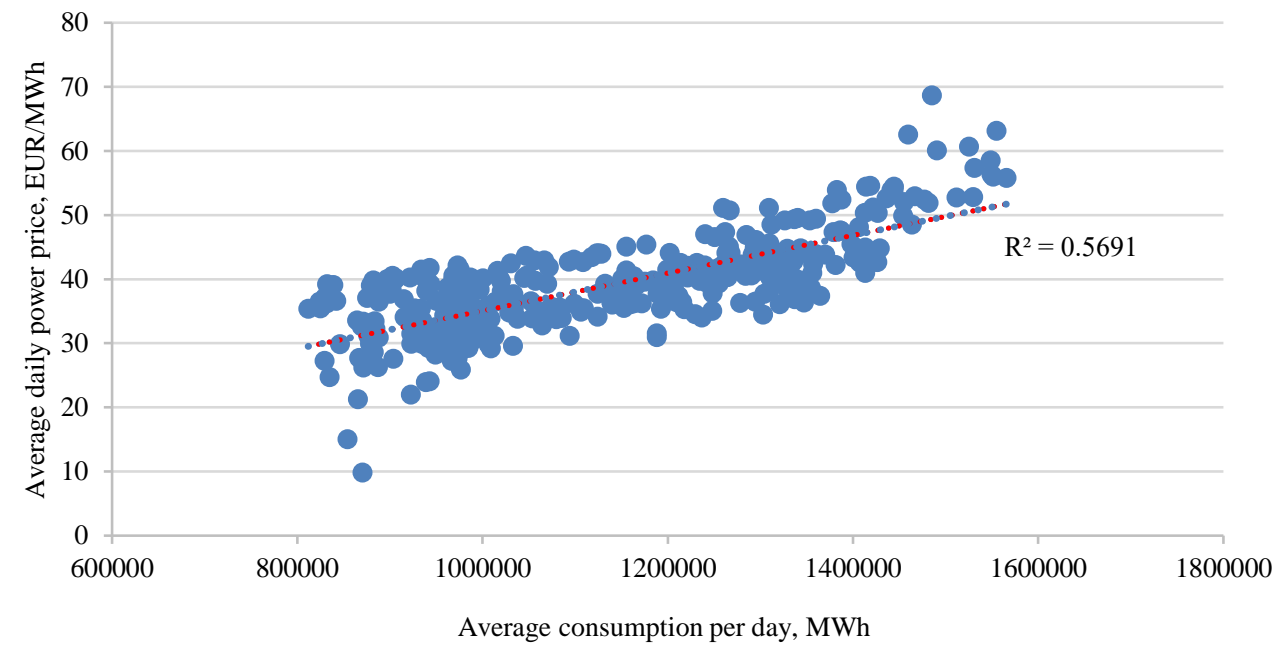

Fig. 6. Correlation between power market price and daily power consumption during 2019 (Data source: Nord Pool Spot, 2020). 
In order to measure an economic effect of the power market price fluctuations caused by intermittent wind power production on the economic performance of wind power producers in Denmark in 2019, the weighted average price per MWh of wind energy sold in "Nord Pool Spot" was calculated and compared with the weighted average trading price. The weighted market price was obtained as the yearly sum of hourly income of power producers (sold volume at the price for specific hour) divided by the total power sold:

$$
p_{T P}=\frac{\sum_{i=1}^{8760}\left(p_{i} E_{i}^{T P}\right)}{\sum_{i=1}^{8760} E_{i}^{T P}}
$$

where

$p_{T P} \quad$ weighted average price of total power sold on electricity market, EUR/MWh;

$p_{i} \quad$ hourly power market price, EUR/MWh;

$E_{i}^{T P}$ total power sold at a given hour, MWh.

The weighted average sales price of wind energy producers was obtained as the yearly sum of hourly income of wind power producers (sold volume at the price for specific hour) divided by the total wind power sold:

$$
p_{W P}=\frac{\sum_{i=1}^{8760}\left(p_{i} E_{i}^{W P}\right)}{\sum_{i=1}^{8760} E_{i}^{W P}}
$$

where

$p_{W P} \quad$ weighted average price of wind power sold on electricity market, EUR/MWh;

$p_{i} \quad$ hourly power market price, EUR/MWh;

$E_{i}^{W P}$ wind power sold at a given hour, MWh.

The calculations reveal that in 2019 wind energy producers sold wind power at a price of 44.27 EUR per MWh while the weighted average market price was 43.96 EUR per MWh. Thus, the price difference is approximately $0.7 \%$, and suggests that income of wind energy producers is only insignificantly affected by price reduction during high-wind periods.

\section{Conclusions}

Despite the fact that analysis of market data did reveal a trend indicating decrease of power market prices with increased share of wind power production, the correlation analysis showed no correlation between these variables, and the $R$-squared value was only 0.0064 for Denmark, which is the country with the highest penetration of wind power in the NordicBaltic region, and even lower (0.003) for the Baltic countries.

Therefore, it was not possible to obtain any functional relationship between increase of the share of wind power and resulting decrease of power market price which could be used in the future modelling of energy systems. However, these observations also indicated, that the impact of intermittent renewable energy sources such as wind power on the power market prices in the longer term is possibly overestimated and may not be substantial even for a market such as Nord Pool Spot, in which the proportion of wind energy can be as high as $30 \%$. It can be assumed that, in general, high availability of wind power leads to a decrease in overall power market prices. However, there are currently no evident signals to prove the assumption that high supply of wind energy provokes somewhat different market reaction from situation when there is a high availability of any other production sources, including hydro energy or combined heat and power plant capacities. It means that the "selfcannibalization effect" of renewable energy suppliers may not have as big of an impact on 
the overall business environment of future investors of renewable energy, as shorter-term power market price fluctuations may suggest. At least, this question calls for more studies in the future, based on the actual power market data.

\section{ACKNOWLEDGEMENTS}

The research is funded by the Ministry of Economics of the Republic of Latvia, project "Assessment and analysis of energy efficiency policy (AAEEP)", project No. VPP-EM-EE-2018/1-0004.

\section{REFERENCES}

[1] Hu J., Harmsen R., Crijns-Graus W., Worrell E., Broek van den M. Identifying barriers to large-scale integration of variable renewable electricity into the electricity market: A literature review of market design. Renewable and Sustainable Energy Reviews 2018:81(P2):2181-2195. https://doi.org/10.1016/j.rser.2017.06.028

[2] Newbery D., Pollitt M. G., Ritz R. A., Strielkowski W. Market design for a high-renewables European electricity system. Renewable and Sustainable Energy Reviews 2018:91:695-707. https://doi.org/10.1016/j.rser.2018.04.025

[3] IEA Analysis. Power. Renewables 2019 - Analysis. [Online]. [Accessed: 20.01.2020]. Available: https://www.iea.org/reports/renewables-2019/power\#abstract.

[4] Lindroos T. J. et al., Baltic Energy Technology Scenarios 2018. Tema Nord $2018: 515$. https://doi.org/10.6027/TN2018-515

[5] IEA Analysis. How will the electricity market of the future work? [Online]. [Accessed: 20.01.2020]. Available: https://www.iea.org/commentaries/how-will-the-electricity-market-of-the-future-work.

[6] Clerici A., Cova B., Callegari G. Decarbonization of the electrical power sector in Europe: An asset, an opportunity or a problem? Energy and Environment 2015:26(1-2):127-142. https://doi.org/10.1260/0958-305X.26.1-2.127

[7] EWEA. Wind energy in Europe 2010. WindEurope, 2011.

[8] EWEA. Wind energy in Europe in 2019. WindEurope, 2020.

[9] Shrimali G., Srinivasan S., Goel S., Nelson D. The effectiveness of federal renewable policies in India. Renewable and Sustainable Energy Reviews 2017:70:538-550. https://doi.org/10.1016/j.rser.2016.10.075

[10] Hu W., Chen Z., Bak-Jensen B. The relationship between electricity price and wind power generation in Danish electricity markets. Proceedings of Asia-Pacific Power and Energy Engineering Conference, APPEEC, 2010. https://doi.org/10.1109/APPEEC.2010.5448739

[11] Pilpola S., Lund P. D. Different flexibility options for better system integration of wind power. Energy Strategy Reviews 2019:26:100368. https://doi.org/10.1016/j.esr.2019.100368

[12] Li Y. Quantifying the impacts of wind power generation in the day-ahead market: The case of Denmark.

[13] Roldan Fernandez J. M., Burgos Payan M., Riquelme Santos J. M. The Merit-Order Effect of Load-Shifting: An Estimate for the Spanish Market. Environmental and Cimate Technologies 2020:24(1):43-57. https://doi.org/10.2478/rtuect-2020-0003

[14] $\mathrm{Li} \mathrm{X}$. The impact of wind power generation on the wholesale electricity price. Evidence from the Swedish electricity market. Master thesis, UMEA Universitet, 2017.

[15] Unger E. A., Ulfarsson G. F., Gardarsson S. M., Matthiasson T. The effect of wind energy production on cross-border electricity pricing: The case of western Denmark in the Nord Pool market. Economic Analysis and Policy 2018:58:121130. https://doi.org/10.1016/j.eap.2018.01.006

[16] Denny E. et al. The impact of increased interconnection on electricity systems with large penetrations of wind generation: A case study of Ireland and Great Britain. Energy Policy 2010:38(11):6946-6954 https://doi.org/10.1016/j.enpol.2010.07.011

[17] You W. et al. Technical and economic assessment of RES penetration by modelling China's existing energy system. Energy 2018:165(PB):900-910. https://doi.org/10.1016/j.energy.2018.10.043

[18] Byers C., Levin T., Botterud A. Capacity market design and renewable energy: Performance incentives, qualifying capacity, and demand curves. Electr. J. 2018:31(1):65-74. https://doi.org/10.1016/j.tej.2018.01.006

[19] Shrimali G., Nelson D., Goel S., Konda C., Kumar R. Renewable deployment in India: Financing costs and implications for policy. Energy Policy 2013:62:28-43. https://doi.org/10.1016/j.enpol.2013.07.071 


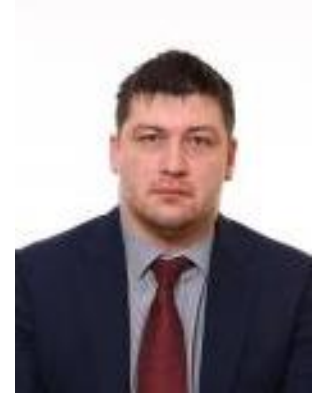

Gunars Valdmanis is a $\mathrm{PhD}$ student at Riga Technical University, Electrical and Environmental Engineering faculty. Previously gained a political science master's degree at the University of Latvia the faculty of Social studies, as well as a master's degree in an environmental science specialist at Riga Technical University, Energy and Electrical engineering and the Vilnius Gediminas Technical University. G. Valdmanis is also the author of several publications devoted to security and economic policy areas. G. Valdmanis' previous professional experience in the field of energy and environment is related to work in the Latvian Association of Electric Power Engineers and Energy Builders, the Department of energy market and infrastructure of the Ministry of Economy, previously gained experience in private business in the field of transport, as well as various mass media.

Email: gunars_valdmanis@inbox.lv

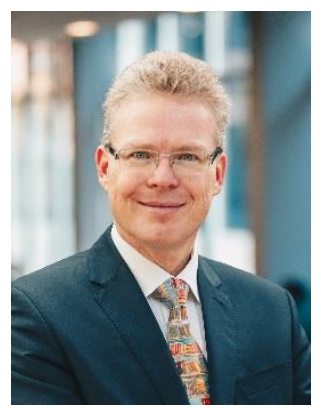

Gatis Bazbauers, Dr. sc. ing., has a diploma of thermal engineering (1990), master of science degree in mechanical engineering (1995), doctor of science degree in engineering (1999) and bachelor's degree in business administration (2002). He works in the Institute of Energy Systems and Environment, Faculty of Electrical and Environmental Engineering at Riga Technical University from the year 2000, and currently is a Professor. He worked as a Managing Director in the energy company "Vattenfall Latvia" (1995-2007), as a Project Manager in the energy consulting company "EEE" (1992-1993) and as an Assistant in the Riga Technical University (1990-1993). The main research interests are district heating systems and cogeneration, energy system planning and economics, renewable energy sources, eco-design, life cycle assessment.

E-mail: Gatis.Bazbauers@ rtu.lv

ORCID iD: https://orcid.org/0000-0001-6996-8472 